\title{
Modulations of cell cycle checkpoints during HCV associated
} disease

\author{
Saira Sarfraz ${ }^{1}$, Saeed Hamid ${ }^{2}$, Syed Ali ${ }^{1}$, Wasim Jafri ${ }^{2}$ and Anwar A Siddiqui*1
}

Address: ${ }^{1}$ Department of Biological and Biomedical Sciences, Aga Khan University, Karachi, Pakistan and ${ }^{2}$ Department of Medicine, Aga Khan University, Karachi, Pakistan

Email: Saira Sarfraz - saira.khalidb@gmail.com; Saeed Hamid - saeed.hamid@aku.edu; Syed Ali - sairee27@yahoo.com; Wasim Jafri - wasim.jafri@aku.edu; Anwar A Siddiqui* - anwar.siddiqui@aku.edu

* Corresponding author

Published: 10 August 2009

BMC Infectious Diseases 2009, 9:125 doi:10.1186/147|-2334-9-125
Received: 19 January 2009

Accepted: 10 August 2009

This article is available from: http://www.biomedcentral.com/I47I-2334/9//25

(C) 2009 Sarfraz et al; licensee BioMed Central Ltd.

This is an Open Access article distributed under the terms of the Creative Commons Attribution License (http://creativecommons.org/licenses/by/2.0), which permits unrestricted use, distribution, and reproduction in any medium, provided the original work is properly cited.

\begin{abstract}
Background: Impaired proliferation of hepatocytes has been reported in chronic Hepatitis $\mathrm{C}$ virus infection. Considering the fundamental role played by cell cycle proteins in controlling cell proliferation, altered regulation of these proteins could significantly contribute to HCV disease progression and subsequent hepatocellular carcinoma (HCC). This study aimed to identify the alterations in cell cycle genes expression with respect to early and advanced disease of chronic $\mathrm{HCV}$ infection.
\end{abstract}

Methods: Using freshly frozen liver biopsies, mRNA levels of 84 cell cycle genes in pooled RNA samples from patients with early or advanced fibrosis of chronic HCV infection were studied. To associate mRNA levels with respective protein levels, four genes (p27, pI5, KNTCI and MAD2LI) with significant changes in mRNA levels $(>2$-fold, $p$-value $<0.05)$ were selected, and their protein expressions were examined in the liver biopsies of 38 chronic hepatitis $C$ patients.

Results: In the early fibrosis group, increased mRNA levels of cell proliferation genes as well as cell cycle inhibitor genes were observed. In the advanced fibrosis group, DNA damage response genes were up-regulated while those associated with chromosomal stability were down-regulated. Increased expression of CDK inhibitor protein p27 was consistent with its mRNA level detected in early group while the same was found to be negatively associated with liver fibrosis. CDK inhibitor protein pl5 was highly expressed in both early and advanced group, but showed no correlation with fibrosis. Among the mitotic checkpoint regulators, expression of $\mathrm{KNTCl}$ was significantly reduced in advanced group while MAD2LI showed a non-significant decrease.

Conclusion: Collectively these results are suggestive of a disrupted cell cycle regulation in HCVinfected liver. The information presented here highlights the potential of identified proteins as predictive factors to identify patients with high risk of cell transformation and HCC development.

\section{Background}

Infection with HCV accounts for a vast majority of viral hepatitis cases. A recent report suggests its prevalence in geographically diverse areas, affecting around 130 million people worldwide [1]. In Pakistan, the frequency of HCV infection is estimated to be around $6 \%$ in general population [2]. These figures are alarming, as patients currently asymptomatic with relatively mild disease may eventually 
progress to complications of chronic liver disease like, cirrhosis, end-stage liver disease and hepatocellular carcinoma (HCC). According to a recent review published by Raza et al., 45\% cases of HCC in Pakistan were found to be positive for HCV antibody [3]. Epidemiological and clinical studies have also demonstrated a causative role of HCV infection in the development of HCC [4], albeit the underlying mechanism is not fully known.

Liver injury is generally believed to be initiated by the death of infected cells afflicting problems of inflammation, regenerative hepatocyte proliferation and fibrosis in the surroundings [5]. In chronic HCV infection, rounds of hepatic cell destruction and regeneration along with fibrosis occur as a result of persistent inflammation. This phenomenon provides the pathogenic basis of HCV associated liver disease. Together, these events keep the dividing hepatocytes susceptible to cellular insult and hence putting them at a greater risk of acquiring mutations.

The molecular events during proliferation are tightly controlled by the cell cycle regulators. During the cell cycle, flawless DNA replication and chromosome segregation are achieved by means of quality control checkpoints that are active at each of the four phases of cell cycle namely Gap1 (G1), DNA synthesis (S), Gap2 (G2) and Mitosis (M). Progression through the phases of cell cycle is driven by temporal activation of specific protein kinase complexes consisting of cyclins and cyclin dependent kinases (CDKs) [6]. In response to cellular insults, such as DNA damage and oxidative stress, inhibitory checkpoint regulators are activated at G1, S and G2 phases and stall the progression of cell cycle [7]. These regulators include DNA damage response genes (RAD1, HUS1, RAD9, ATM, ATR and p53) [8] and members of CDK inhibitor family, p16 (CDKN2A), p15 (CDKN2B), p21 (CDKN1A) and p27 (CDKN1B) [9]. In the subsequent $M$ phase, mitotic checkpoint proteins of MAD and BUB families are responsible for a proper chromosomal segregation during cell division [10].

Studies performed on hepatic biopsies from chronic hepatitis $\mathrm{C}$ patients have shown an imbalance at G1/S checkpoint of cell cycle $[11,12]$. In fact, the report from Marshal et al showed a G1 arrest in hepatocytes characterized by over expression of CDK inhibitor p21. In our previous work [13] this arrest was further described by showing altered expression of tumor suppressor p53 and apoptotic proteins Caspase-3 and Bcl-2. Although these reports suggest modulations of cell cycle events in hepatocytes during the course of HCV-mediated disease progression, a detailed analysis of cell cycle regulators involved at other checkpoints still needs to be performed.
In order to determine the contribution of cell cycle genes in $\mathrm{HCV}$-induced disease progression, we have studied the altered expression of cell cycle genes in HCV infected liver biopsy tissues. This might be considered as an initial step towards the prevention of chronic HCV disease progression into HCC. The mRNA expression of eighty four cell cycle genes were first examined in pooled RNA samples from patients with early or advanced HCV disease, and in normal liver RNA of an uninfected individual. This analysis identifies a list of differentially expressed genes involved at cell cycle checkpoints. The translational levels of four differentially expressed genes (p15, p27, KNTC1 and MAD2L1) were further examined. These genes were selected on the basis of their crucial roles at G1/S and mitotic checkpoints, in 38 chronic HCV infected tissues using immunohistochemistry or western blotting. The results showed significant association of p27 and KNTC1 with the progression of liver fibrosis.

\section{Methods \\ Tissue Samples}

After obtaining approval from the ethical review committee at the Aga Khan University, and informed consent from the patients, liver biopsy specimens were collected from thirty eight untreated chronic hepatitis $\mathrm{C}$ patients and six non-viral hepatitis patients. Each sample was apportioned into two pieces; one was frozen at $-80^{\circ} \mathrm{C}$ and other was fixed in formalin. An experienced liver pathologist performed the histopathological grading and staging on formalin-fixed paraffin embedded tissue samples, employing Batts and Ludwig scoring system [14]. Fibrosis stage was F0, F1, F2, F3 and F4 in 5, 9, 6, 10 and 8 patients, respectively. Paraffin embedded tissues from individuals who had normal liver histology $(n=4)$ as determined by light microscopy, were also included as controls in the immunohistochemistry experiments.

\section{Sample Preparation and Quantitative RT-PCR}

For transcriptional studies eight liver specimens were selected; four with F0-1, designated as early HCV disease and four with F3-4, designated as advanced HCV disease (Table 1a). Total RNA from frozen liver tissues was extracted in TRIzol reagent (Invitrogen, MD, USA). The extract was made DNA free by digestion with RNase-free DNase (Invitrogen, MD, USA) using $0.2 \mathrm{U} / 1 \mu \mathrm{g}$ RNA and incubation at $37^{\circ} \mathrm{C}$ for 10 to 30 minutes followed by DNase inactivation at $75^{\circ} \mathrm{C}$ for 5 minutes. For PCR array experiments, human cell cycle $\mathrm{RT}^{2}$ profiler PCR array (SuperArray Bioscience, MD) was used to simultaneously examine the mRNA levels of 89 cell cycle genes (list of genes is available at http://www.superarray.com), including five "housekeeping genes" in pooled RNA samples from early and advanced HCV group. The pooled samples were prepared by mixing equal amounts of liver tissue RNA from four patients of each group. Previous studies 
Table I: Demographic features of the study patients

\begin{tabular}{|c|c|c|c|c|c|}
\hline & Mean Age (years) & Gender (male/female) & Virus infection & *Stage of Fibrosis & $\begin{array}{c}* \text { Grade of } \\
\text { Inflammation }\end{array}$ \\
\hline \multicolumn{6}{|c|}{ a) Patients included in PCR array experiments } \\
\hline $\begin{array}{r}\text { Early HCV } \\
(n=4)\end{array}$ & $40 \pm 6.2$ & $2 / 2$ & $\mathrm{HCV}$ & $0-1$ & $0-1$ \\
\hline $\begin{array}{r}\text { Advanced } \\
\mathrm{HCV} \\
(\mathrm{n}=4)\end{array}$ & $53 \pm 4.9$ & $2 / 2$ & $\mathrm{HCV}$ & $3-4$ & $3-4$ \\
\hline \multicolumn{6}{|c|}{ b) Patients included in Immunohistochemistry experiments } \\
\hline $\begin{array}{r}\text { Chronic HCV } \\
(n=38)\end{array}$ & $42+9.3$ & $18 / 20$ & $\mathrm{HCV}$ & $0-4$ & $1-4$ \\
\hline Non-viral hepatitis $(n=6)$ & $49 \pm 2.1$ & $2 / 4$ & None & $1-4$ & $1-3$ \\
\hline $\begin{array}{r}\text { Normal } \\
(\mathrm{n}=4)\end{array}$ & $26 \pm 4.0$ & $2 / 2$ & None & - & - \\
\hline
\end{tabular}

\footnotetext{
* Histopathological staging and grading of tissue samples were performed according to Batts Ludwig scoring system.
}

have described RNA pooling as an appropriate initial screening approach [15]. Given the limited availability of liver biopsies from normal liver patients, total RNA of normal, non-diseased liver purchased from Ambion (Palo Alto, CA) was used as a reference standard in these experiments. Reverse transcription was performed at $37^{\circ} \mathrm{C}$ for 1 hour with ReactionReady first strand cDNA Synthesis Kit (SuperArray Biosciences, MD) using $1 \mu \mathrm{g}$ of total RNA. The synthesized cDNA was subjected to PCR amplification using $\mathrm{RT}^{2}$ profiler PCR arrays according to manufacturers' instructions. The PCR conditions used were as follows; $95^{\circ} \mathrm{C}$ for 10 minutes followed by 40 cycles at $95^{\circ} \mathrm{C}$ for 30 seconds and $60^{\circ} \mathrm{C}$ for one minute. Each experiment was performed in duplicate or triplicate on iCycler iQ Real Time PCR system (BioRad Laboratories). Of the 5 housekeeping genes, GAPDH was used for normalization. Fold change in expression of different groups was calculated using $\Delta \Delta \mathrm{C}^{\mathrm{t}}$ method [16]. A p-value of $\leq$ 0.05 and a fold change of $\geq 2$ in gene expression was taken as significant.

\section{Antibodies}

The following antibodies were used for immunohistochemistry at the dilutions given in parentheses; Mouse monoclonal antibodies to p27 (DCS-72.F6, 1:50) and p15 (15P06, 1:25) were purchased from Abcam (Cambridge, UK). For western blotting monoclonal antibodies against MAD2L1 (17D10, 1:500) and KNTC1 (10H4, $1: 1000)$ were purchased from Abcam (Cambridge, UK) and AbNova (Taiwan), respectively.

\section{Immunohistochemistry}

For immunohistochemistry 4-micron thin sections of paraffin-embedded liver tissues (Table 1b) were deparaffinized and rehydrated using a xylene-alcohol sequential wash. The sections were then subjected to antigen retrieval by heating in $0.01 \mathrm{M}$ citrate buffer ( $\mathrm{pH}$ 6.0) using a pressure-cooker. EnVision Kit (Dako, Hamburg, Germany) was used for immunostaining essentially following the manufacturer's protocol. Briefly, endogenous peroxidase was blocked for $5 \mathrm{~min}$ in $0.03 \% \mathrm{H}_{2} \mathrm{O}_{2}$. Sections washed in Tris-buffered saline with Tween 20 (TBST; $0.05 \mathrm{~mol} / \mathrm{l}$ Tris and $0.15 \mathrm{~mol} / \mathrm{l} \mathrm{NaCl}, \mathrm{pH} 7.6,0.1 \%$ Tween 20 ) were incubated with primary antibodies for 1 hour at room temperature. Thereafter, a horseradish peroxidase (HRP)-labelled polymer conjugated with a secondary antibody was applied. The staining was visualized with 3, 3'-diaminobenzidine tetrahydrochloride (DAB). Finally, the slides were counterstained with haematoxylin and mounted in DPEX for examination. The immunostained sections were examined using Nikon Eclipse E8000 and image analysis system, (Nikon, Japan). Quantification of positive hepatocytes was undertaken by two independent observers counting approximately 1000 hepatocytes at magnification $400 \times$ in five randomly selected fields. The positive hepatocytes were expressed as a percentage of the total cells counted in each case and values for subsequent analysis were obtained from the mean of the two independent observations.

\section{Protein Extraction and Western Blotting}

Proteins were isolated from the organic phase of TRIzol extraction as described in manufacturer's protocol. Isolated proteins were heat denatured in electrophoresis sample buffer (62 mM Tris-Cl, pH 6.8, 0.2\% glycerol, 2\% SDS, $0.04 \% \quad \beta$-mercaptoethanol, $0.04 \%$ bromophenol blue) and loaded onto $12 \%$ SDS-polyacrylamide gel. After electrophoresis on the gel, separated protein bands were transferred onto a PVDF membrane (Amersham, Germany). Membranes were blocked with 5\% Blotting Grade 
Blocker non-fat dry milk powder overnight at $4{ }^{\circ} \mathrm{C}$. The membrane was incubated with primary antibody diluted in $1 \times$ TBST (Tris-buffered saline, $0.1 \%$ Tween 20) on an orbital shaker, followed by three washings in TBST for 10 mins. After washing, the membrane was incubated with horse radish peroxidase-labelled anti-mouse IgG $(1: 10,000)$ for $1 \mathrm{~h}$ on an orbital shaker at room temperature. Membrane was washed with $1 \times$ TBST three times for 10 min on a shaker. The blot was developed with ECL Plus reagent (Amersham, Germany) according to manufacturer's instructions. Actin was included as internal loading control and detected by Anti-actin (Santa Cruz). Band intensities were measured using Image J software (NIH, USA).

\section{Statistical Analysis}

Significant fold change in mRNA levels of each gene between the groups was tested using $t$-test as indicated by the manufacturer (SuperArray, MD). Analyses of immunostaining data were performed using the Statistical Package for Social Sciences (SPSS, 14.0). Association between the expression of p27, p15, KNTC1 and MAD2L1with histological feature fibrosis was analyzed using Johnkhere Terpestra test or Mann Whitney U-test. Correlations among the groups were evaluated by Spearman's rank correlation coefficient. A p-value of less than 0.05 was considered significant.

\section{Results}

\section{Transcriptional Profile of Cell Cycle Pathway Genes}

In order to assess the extent of modulation in cell cycle gene expression during chronic infection, PCR arrays of 84 cell cycle genes were performed in RNA samples separately pooled from early $\mathrm{HCV}$, advanced $\mathrm{HCV}$ and commercial preparation of human normal liver RNA. The mean GAPDH threshold cycle $(\mathrm{Ct})$ values for early $\mathrm{HCV}$, advanced HCV and normal liver were $22.45 \pm 0.5,22.95$ \pm 0.42 and $22.0 \pm 0.21$ respectively. Comparisons of mRNA expressions of cell cycle genes, made between, 1) normal liver to early HCV and 2) early HCV to advanced $\mathrm{HCV}$, revealed that fifteen (18\%) of the 84 cell cycle genes were not detectable in any of the comparative groups, when Ct value greater than 35 was applied as a cutoff for significant expression.

The mRNA expression of 22 (31\%) of the remaining 69 genes showed more than 2 -fold change in early HCV versus normal liver (Table 2). Seven (32\%) of these showed significant increase which include proliferation genes Mcm-2 and cyclin E1, DNA repair gene GADD45 $\alpha$ (Growth arrest and DNA damage $45 \alpha$ ), CDK inhibitor CDKN1B/p27 and G2-M phase regulatory genes KNTC1, DNM2 and CDC16 (see additional file 1).
In early versus advanced HCV comparison, 23 (33\%) of the 69 genes showed more than 2-fold change (Table 3 ). Nine (29\%) of these genes were significantly differentially expressed which include DNA damage response genes RPA3, RAD1, HUS1 and CDK inhibitors CDKN2B/p15, CDKN3 that were found up-regulated whereas tumor suppressor protein p53 and mitotic checkpoint protein MAD2L1 were found down regulated (see additional file $1)$.

\section{Protein Expression of CDK Inhibitors}

Experiments performed to evaluate the differential expression of cell cycle genes showed significant change in the expression of CDK inhibitors p27 and p15. Further investigation focusing on the expression of their corresponding proteins in paraffin embedded sections from 38 chronic hepatitis $\mathrm{C}$ patients (14 cases with F0 or F1, 6 cases with F2 and 18 cases with F3 or F4) resulted in varied profile. The p27 protein was found up-regulated in normal to early HCV while the p15 levels appeared to remain unaltered in early to advanced HCV. The immunostaining of each protein was localized in the nucleus of hepatocytes (Figure 1 \&2) with few cases showing positivity in portal vein area as well. Expression of p27 was detected in the liver of $30 / 38(78.9 \%)$ patients with chronic HCV infection. The percentage of p27 positive hepatocytes in early $\mathrm{HCV}$ (median $=22.6 \%$, range $=4.3-37.4$ ) was significantly higher as compared to normal liver ( median $=4 \%$, range $=1.3-6.3)($ Mann-Whitney U test, $\mathrm{p}=0.001)$ which was similar to the observations at transcriptional level. In advanced HCV the median and range of p27 expression were $17.3 \%$ and 3.0 - 32.0, respectively. The association of p27 expression with HCV-related F0 to F4 showed a significant decrease in p27 expression with the progression of fibrosis (Johnkhere Terpestra Test, $\mathrm{p}=0.04$, Figure 3). In non-viral hepatitis, p27 expression was rarely detected (see additional file 2).

Immunostaining of p15 was not evident in normal liver and non-viral hepatitis except in 1 case see additional file 2). p15 expression was nonetheless observed in $27 / 38$ (71\%) chronic HCV infected liver tissues. In contrast to what was observed at mRNA level a non-significant decrease in p15 expression was observed in early to advanced $\mathrm{HCV}$ comparison (median $=25 \%$, range $=0-39$ versus $21 \%$, range $=13-37$ ). Likewise, no significant association was found with the progression of fibrosis.

\section{Protein Expression of Mitotic Checkpoint Regulators}

Two of the mitotic checkpoint proteins KNTC1 and MAD2L1 showed significant alterations in cell cycle array experiments. Owing to the limited amount of total proteins available from fresh frozen liver biopsies, the protein levels of both of these mitotic regulators were analyzed in 25 out of 38 chronic HCV patients and 4 non-viral hepa- 
Table 2: List of differentially expressed cell cycle genes $>2$ fold in early $\mathrm{HCV}$ relative to normal liver.

\begin{tabular}{llll}
\hline Gene Symbol & Average $C_{t}$ Early HCV & Average $C_{t}$ Normal & $\begin{array}{l}\text { T-test } \\
\text { p-value }\end{array}$ \\
\hline
\end{tabular}

Cell cycle progression/cell proliferation genes

\begin{tabular}{lllll}
\hline MCM2 & 30.85 & 33.4 & 0.05 & 7.670 \\
CDC2 & 32.5 & 34.15 & 0.36 & 4.79 \\
MCM5 & 28.15 & 29.5 & 0.16 & 3.390 \\
MCM3 & 28.0 & 29.1 & 0.11 & 3.100 \\
CCNEI & 33.6 & 34.9 & 0.05 & 4.76 \\
\hline
\end{tabular}

CDK Inhibitors

\begin{tabular}{llll}
\hline CDKNIA & 27.5 & 28.2 & 0.258 \\
CDKNIB & 27.65 & 28.6 & 0.034 \\
\hline
\end{tabular}

G2/M checkpoint gene

\begin{tabular}{llll}
\hline GADD45A & 27.15 & 29.8 & 0.03 \\
DNM2 & 31.75 & 29.6 & 0.000 \\
KPNA2 & 31.3 & 29.25 & -2.65 \\
\end{tabular}

Mitotic checkpoint genes

\begin{tabular}{|c|c|c|c|c|}
\hline KNTCI & 31.6 & 34.4 & 0.04 & 9.19 \\
\hline CKSIB & 31.0 & 33.5 & 0.17 & 7.200 \\
\hline MAD2LI & 32 & 34.55 & 0.077 & 7.07 \\
\hline CDC34 & 30.0 & 31.3 & 0.35 & 3.4 \\
\hline $\mathrm{CDCl} 6$ & 32.6 & 30.8 & 0.027 & -2.16 \\
\hline
\end{tabular}

DNA damage response genes

\begin{tabular}{llll}
\hline CHEKI & 32.35 & 33.70 & 3.09 \\
HUSI & 29.65 & 27.05 & 0.24 \\
\end{tabular}

\section{Cell cycle Regulators}

\begin{tabular}{|c|c|c|c|c|}
\hline HERC5 & 29.3 & 33.7 & 0.07 & 20.393 \\
\hline CCNG2 & 29.85 & 32.3 & 0.11 & 6.400 \\
\hline RBBP8 & 31.7 & 30 & 0.108 & -2.300 \\
\hline $\mathrm{BCL} 2$ & 29.65 & 31.60 & 0.052 & 3.10 \\
\hline UBEI & 29.55 & 27.4 & 0.206 & -3.500 \\
\hline
\end{tabular}

The values present average $C_{t}$ values without normalization and fold differences observed in Real time PCR and $p$-values of $T$-test (values $\leq 0.05$ are in bold). 
Table 3: List of differentially expressed cell cycle genes $>2$ fold in advanced HCV relative to early HCV

\begin{tabular}{llll}
\hline Gene symbol & Average $C_{t}$ Adv. $\mathrm{HCV}$ & Average $C_{t}$ Early HCV & $\begin{array}{l}\text { T-test } \\
\text { p-value }\end{array}$ \\
\hline
\end{tabular}

\section{Cell proliferation genes}

\begin{tabular}{lllll}
\hline CCNDI & 32.65 & 31.00 & 0.14 & -2.22 \\
CCND2 & 31.3 & 32.35 & 0.05 & 5.00 \\
CDK2 & 32.1 & 30.3 & 0.6 & -2.46 \\
\hline
\end{tabular}

CDK inhibitors

\begin{tabular}{lllll}
\hline CDKN2B & 32.4 & 33.50 & 0.04 & 3.03 \\
CDKN3 & 34.20 & 32.73 & 0.05 & 5.46 \\
CDKNIB & 29.4 & 27.7 & 0.5 & -2.3 \\
\hline
\end{tabular}

G2/M checkpoint gene

\begin{tabular}{lllll}
\hline KPNA2 & 30.85 & 31.3 & 0.98 & 2.75 \\
HERC5 & 33.05 & 29.3 & 0.217 & -8.70 \\
\hline
\end{tabular}

DNA damage response genes

\begin{tabular}{lllll}
\hline ATR & 31.9 & 35 & 0.30 & 10.50 \\
RADI & 30.4 & 32.8 & $\mathbf{0 . 0 5}$ & 6.46 \\
HUSI & 27.55 & 29.65 & $\mathbf{0 . 0 5}$ & 6.06 \\
RADI7 & 28.45 & 30.35 & 0.057 & 5.27 \\
RPA3 & 33.3 & 35.0 & 0.01 & 4.6 \\
*TP53 & 30.80 & 27.03 & $\mathbf{0 . 0 4}$ & -2.79 \\
\hline
\end{tabular}

Mitotic checkpoint regulators

\begin{tabular}{lllll}
\hline MAD2LI & 35 & 32 & 0.04 & -5.6 \\
CDC34 & 32.65 & 30.00 & 0.025 & -4.4 \\
\hline
\end{tabular}

\section{Cell cycle regulation}

\begin{tabular}{lllll}
\hline CCNH & 32.85 & 35.0 & 0.5 & 5.00 \\
CDK8 & 28.7 & 30.5 & 0.07 & 4.92 \\
CCNG2 & 27.8 & 29.85 & 0.09 & 5.86 \\
CKS2 & 30.7 & 32.15 & 0.23 & 3.86 \\
CULI & 30.6 & 28.3 & 0.65 & -3.48 \\
TFDP2 & 28.2 & 30 & 0.08 & 4.92 \\
CCNTI & 28.6 & 31.15 & 0.08 & 4.59 \\
\hline
\end{tabular}

The values present average $C_{t}$ values without normalization and fold differences observed in Real time PCR and $p$-values of T-test (values $\leq 0.05$ are in bold). 

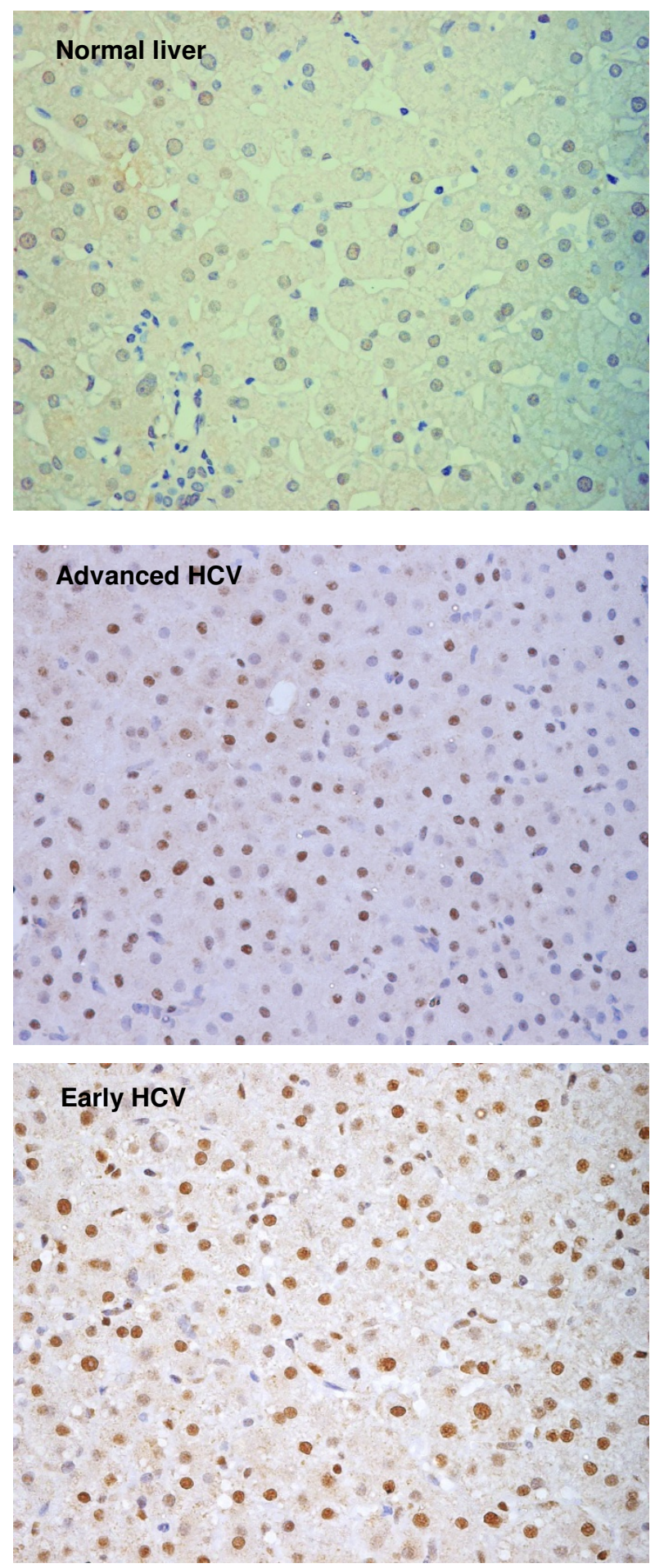

\section{Figure I}

Expression of CDK inhibitor p27. Immunohistochemistry of p27 in normal liver and chronic HCV-infected liver with Early and Advanced HCV. Nuclear expression of the protein was observed in hepatocytes. Positive hepatocytes are stained brown (Mayer hematoxylin, magnification 400x). 

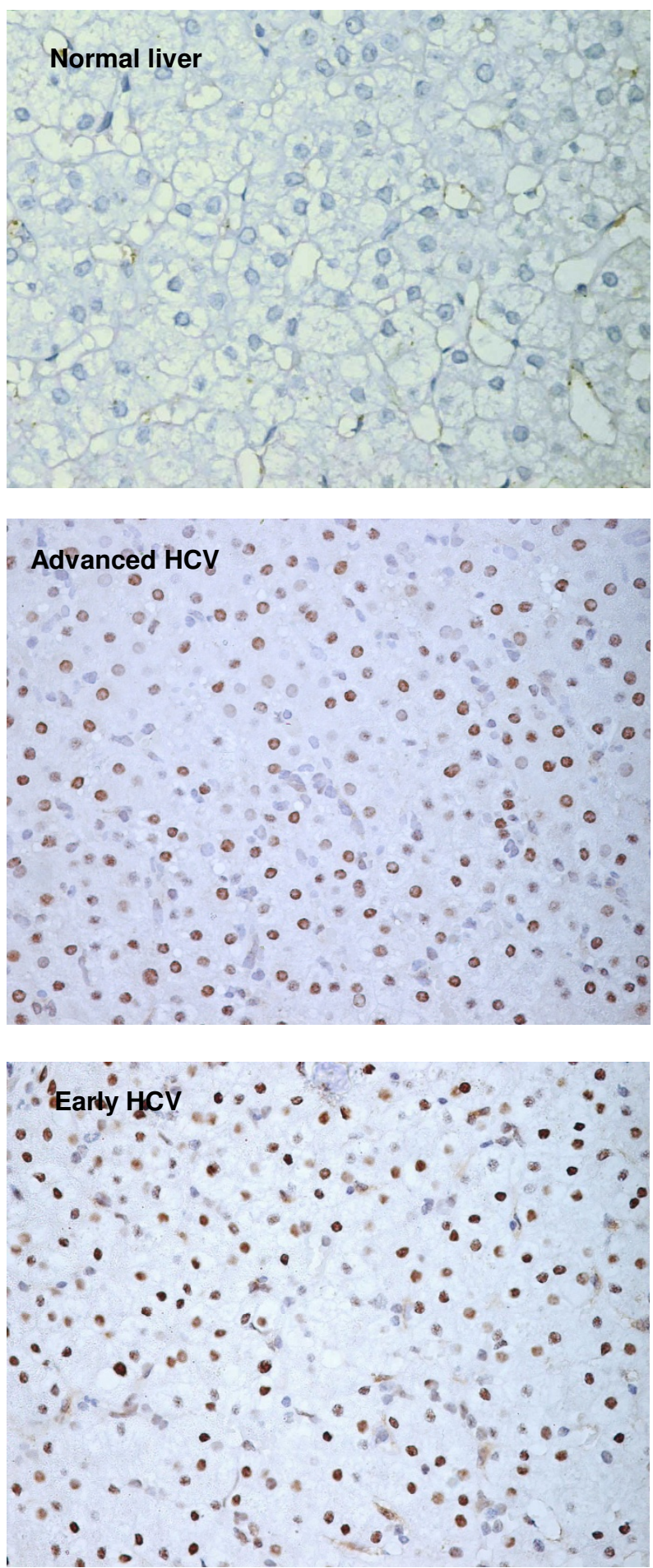

\section{Figure 2}

Expression of CDK inhibitor p I 5. Immunohistochemistry of pI 5 in normal liver and chronic HCV-infected liver with Early and Advanced HCV. Nuclear expression of the protein was observed in hepatocytes. Positive hepatocytes are stained brown (Mayer hematoxylin, magnification 400x). 


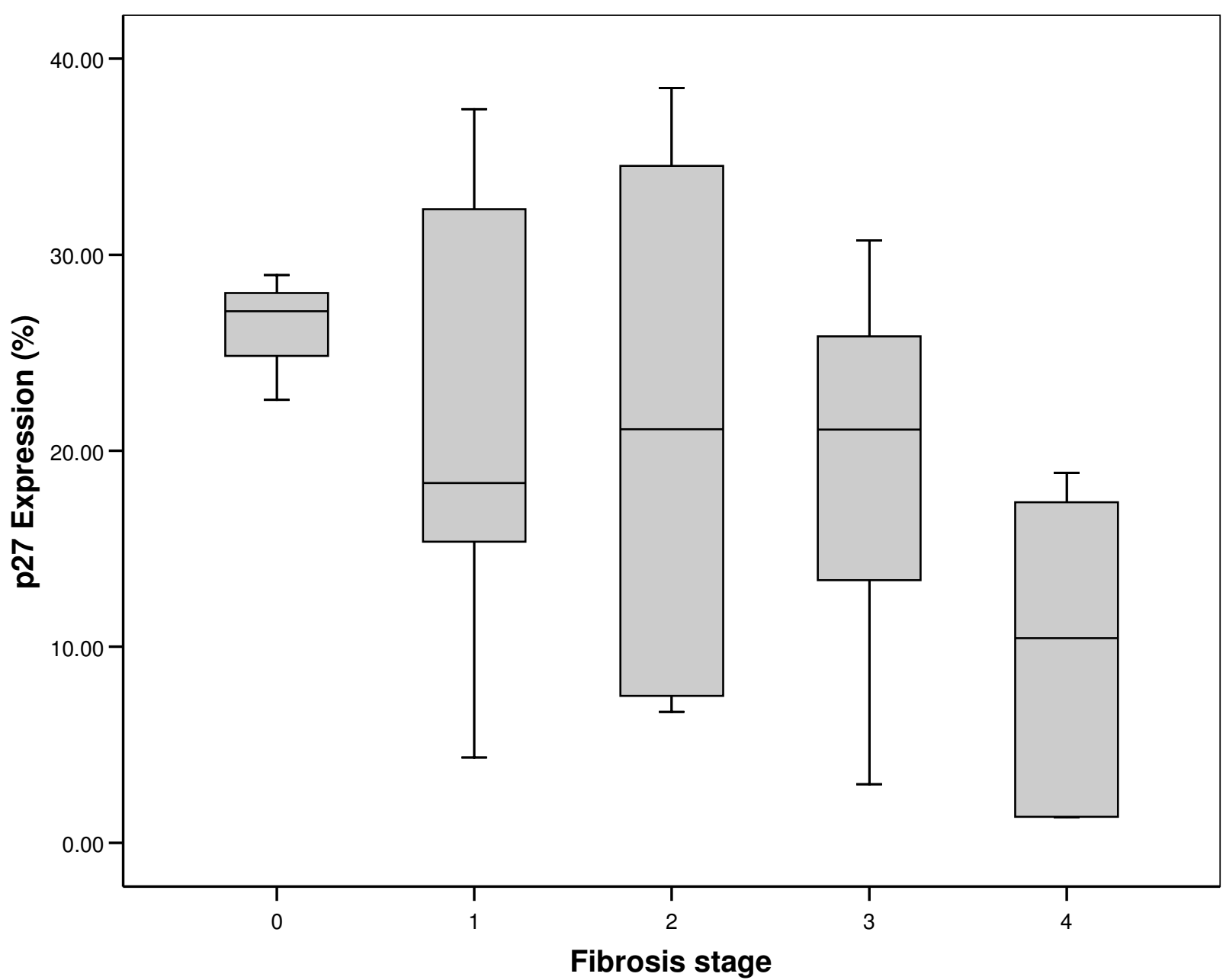

\section{Figure 3}

Negative Association of p27 with fibrosis. Box-plot graphic display of p27 expression in hepatocytes of chronic HCV patients grouped according to fibrosis stage. The horizontal bar in middle of the box represents the median, the box stretches between the $25^{\text {th }}$ and $75^{\text {th }}$ percentile, and the upper and lower lines extend to the range of the data. (Jonckeere-Terpstra test $P$ $=0.04)$.

titis patients. Western blot analysis of KNTC1 detected its band in 20/25 chronic HCV patients and in 2/4 non-viral hepatitis patients (Figure $4 \mathrm{a})$. A significant reduction $(>2$ fold, $\mathrm{p}<0.01$ ) in total KNTC1 levels was observed in advanced HCV as compared to early HCV (Figure 4b). The band of MAD2L1 was also detectable in 17/25 patients while in non-viral hepatitis it was not detectable (Figure 4c). Consistent with the observations at mRNA levels a slight decrease in its expression in advanced HCV group was observed but that was not found statistically significant (Figure 4d).

\section{Discussion}

In the present study, an unbiased PCR array approach containing 84 cell cycle genes was applied on pooled RNA samples, to identify altered gene expression in HCV-associated liver disease. This analysis led to the identification of differentially expressed genes involved at cell cycle checkpoints, which may play a role in disease pathogenesis. Further investigation at protein level of four differentially expressed genes, selected on the basis of their crucial role in cell cycle regulation confirms the modulations in the expression of CDK inhibitor p27 and mitotic checkpoint genes MAD2L1 and KNTC1. It is important to note that these cell cycle proteins have not been implicated previously in chronic liver disease. Moreover, the association 
a)

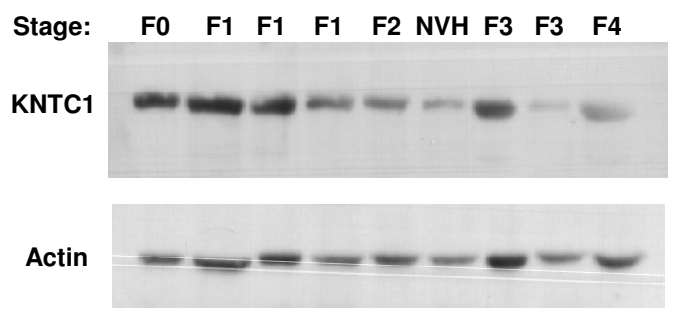

b)

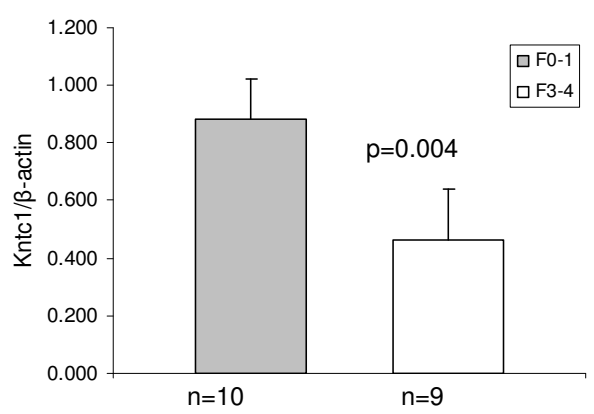

c)

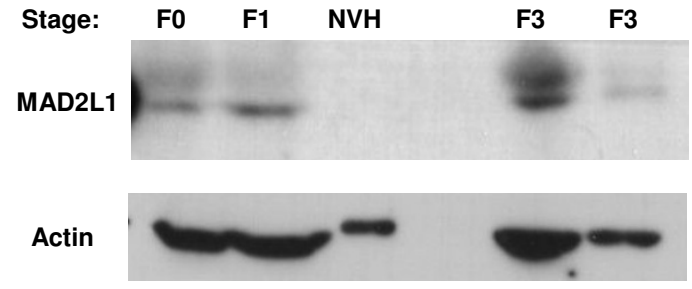

d)

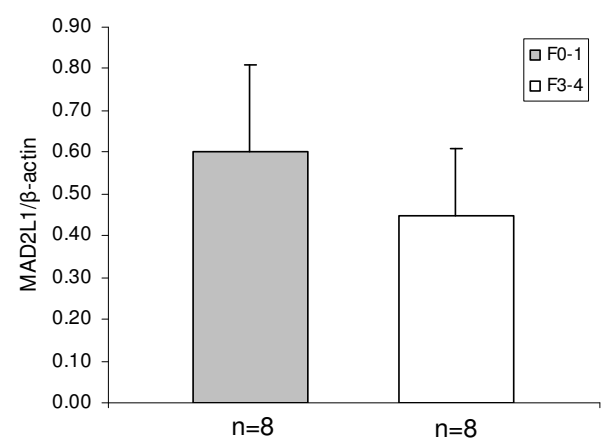

\section{Figure 4}

Reduced expression of mitotic checkpoint genes in chronic HCV patients. a \& c) Western blotting for MAD2LI and KNTCI was done in total protein extracts prepared from biopsy specimens of chronic hepatitis $\mathrm{C}$ or Non-viral hepatitis patients (NVH). Following SDS-PAGE (I $2 \%$ gel) and transfer, the nitrocellulose membranes were probed with monoclonal antibodies to MAD2LI, which recognizes both phosphorylated and de-phosphorylated forms and KNTCI. b \& d) Densitometry analysis of total MAD2LI or KNTCI expression normalized to their respective loading controls ( $\beta$-actin) was done using Image J software. The number of samples analyzed in each group $(n)$ is indicated below each column. The $p$-values at the top of the column compare early HCV to advanced HCV. Represented are mean \pm S.D.

of p27 and KNTC1 expression with liver fibrosis suggests a role of these markers in the progression of liver disease.

Persistent inflammation and cell destruction during HCV infection has been suggested to induce proliferation of normally quiescent hepatocytes [17-19], which helps in restoring liver mass and maintaining hepatic function. Moreover, previous reports including our own have shown an arrested cell cycle in hepatocytes, during HCV infection [12,13]. Consistent with these data we found more than 3 fold increase in the mRNA levels of proliferation related genes Mcm-2, -3, -5, CDC2 and cyclin in early HCV group while the mRNA levels of cell cycle inhibitors p27, GADD45A, MAD2L1 and KNTC1 were also found to be significantly increased (Table 2). These transcriptional changes suggest a mixed population of cells in the infected livers of chronic hepatitis $\mathrm{C}$ some of which are in proliferating state while others in an arrested state. In advanced HCV, cell cycle inhibitors p27 and MAD2L1 were found down-regulated while p15/ CDKN2B and CDKN3 were up-regulated. More than four fold increase was also observed in the mRNA levels of DNA damage response genes ATR, HUS1, RAD1, RPA3 and RAD17 (Table 3) suggesting increased DNA damage. These alterations were also accompanied by the down-regulation of tumor suppressor p53. Taken together these results are suggestive of deregulated cell cycle in chronic $\mathrm{HCV}$ infection that is considered as a consistent event in $\operatorname{HCC}[20,21]$. 
Association of CDK inhibitor p21 with impaired liver regeneration and progressive liver fibrosis has been reported earlier [22]. In the current study, analysis at protein level by immunohistochemistry in HCV-infected hepatic biopsies showed a significant increase in the expression of p27 protein (Figure 1) that belongs to the same KIP family as p21. This protein is involved in inhibiting cell cycle progression at both G1 and S phases and is also defined as a tumor suppressor protein [23]. Interestingly, an inverse relationship between $\mathrm{p} 27$ protein expression and progression of liver fibrosis from F0 to F4 was found (Figure 3 ). It would be pertinent to mention here that mouse models of chronic injury induced-liver tumorgenesis have shown that loss of p27 in advanced stages of disease promotes tumor cell proliferation [24]. These observations signify the potential of p27 as a marker for prognostic implications in chronic HCV disease.

In contrast to p27, immunohistochemical evaluation of G1 phase inhibitor p15 revealed no significant difference in advanced HCV as compared to early HCV that conflicts with the changes observed at mRNA level. This inconsistency might have been due to decreased stability of p15 protein in advanced disease stages that increased the transcription through a regulatory feedback mechanism to maintain its levels. Another explanation for this inconsistency could be the use of pooled samples of whole liver lysates for mRNA expression while immunohistochemistry was done on individual formalin fixed paraffin embedded biopsies. Together, the expression of p27 and p15 in non-dividing hepatocytes might represent the population of cells which are arrested in cell cycle and not participating much in liver compensation, but are more active metabolically.

Defects in chromosomal segregation are a common feature of liver tumor cells suggesting a possible role of mitosis deregulation in the pathogenesis of HCC [25]. While examining the alterations of cell cycle genes in early and advanced $\mathrm{HCV}$, we found altered expression of mitotic checkpoint genes, MAD2L1, KNTC1, CDC16 and CDC34. KNTC1, also known as "rough deal protein" (ROD) is part of a complex involved in elaborating an inhibitory signal due to improper chromosomal alignment during cell division [26], while member of Mad2 family, MAD2L1, participates in inhibiting Anaphase promoting complex (APC) [27] from ubiquitinating securin, whose degradation is a prerequisite for sister chromatid separation and mitosis. Considering the crucial roles of KNTC1 and MAD2L1 in chromosomal segregation, we analyzed their respective proteins by western blotting. Results showed increased levels of both of these proteins in early HCV that is suggestive of mitotic checkpoint activation or mitotic arrest in the liver cells. This is consistent with the downregulation of CDC16, which is a component of APC and promote chromosomal segregation. Importantly, KNTC1 expression significantly decreases in advanced stages of $\mathrm{HCV}$ group as compared to early HCV while the expression of MAD2L1 showed a modest reduction in advanced HCV group (Figure 4). However, a possibility of error in assessing these changes could come about due to the fact that the expression of reference gene, $\beta$-actin also increases with the progression of liver fibrosis.

The role of KNTC1 in human cancers is not well documented, however, a single report describes mutation in this gene in colorectal carcinoma [28]. On the other hand, depletion or reduced expression of MAD2 gene has been reported in mammalian cells with loss of mitotic checkpoint and subsequent chromosomal instability [29,30]. Thus, low expression of these mitotic checkpoint regulators in advanced HCV might reflect loss of mitotic checkpoint control that could render cells to chromosomal instability. This hypothesis is also supported by a previous study which showed presence of near-aneuploidy DNA content in liver specimens from chronic hepatitis C patients [11].

The altered expression of cell cycle regulators observed in present study might be specific to hepatitis $\mathrm{C}$ as it was rarely observed in non-viral hepatitis patients. Nevertheless, the low number of control liver samples, hold back in achieving statistically significant differences between the two groups, with varying degrees of fibrosis.

\section{Conclusion}

The analysis of cell cycle regulators showed altered expression of G1/S and M phase inhibitors in chronic HCV infection which either arrest or delays the progression through $\mathrm{G} 1$ and $\mathrm{S}$ phase as well as $\mathrm{M}$ phase, latter being not reported earlier in chronic hepatitis $\mathrm{C}$ patients. These cell cycle perturbations might be a consequence of increased DNA damage or persistent inflammation during viral infection that in turn could increase genetic instability and cell transformation. The information presented here laid down the basis for future studies to evaluate the activation of the identified cell cycle genes in chronic hepatitis C patients as well as HCC patients infected with HCV. These studies would be helpful to identify patients with high risk of cell transformation and HCC development.

\section{Competing interests}

The authors declare that they have no competing interests.

\section{Authors' contributions}

SS formulated the idea, conducted the experimental work and wrote the first draft of the manuscript. SH helped in the formulation of the study, supervised the acquisition of study samples, research protocol and the development of 
the manuscript. SA was involved in the analysis and interpretation of the data and was involved in drafting the manuscript. WJ was involved in the supervision of the study and acquisition of study samples. AS helped in the conception and design of the study and revised the manuscript critically for important intellectual content. All authors read and approved the final version of the manuscript.

\section{Additional material}

\section{Additional file 1}

Bar graph of differentially expressed cell cycle genes in early and advanced HCV. Human Cell cycle RT-PCR-Array of pooled RNA samples from HCV infected liver specimens (early and advanced HCV) and normal liver RNA sample were performed. Bars represent fold differences in $m R N A$ levels ( $>2$ fold, $p<0.05$ ) of a particular gene when comparing a) Normal liver to Early HCV and b) Early HCV to Advanced HCV. Positive fold change values indicate that the transcript is up regulated, while negative values indicate that the transcript is down regulated.

Click here for file

[http://www.biomedcentral.com/content/supplementary/14712334-9-125-S1.ppt]

\section{Additional file 2}

Expression of CDK inhibitors in liver tissues with non-viral hepatitis. Click here for file

[http://www.biomedcentral.com/content/supplementary/14712334-9-125-S2.doc]

\section{Acknowledgements}

This work was supported by a grant awarded to SS by the University Research Council, Aga Khan University, Karachi, Pakistan. We thank all the patients and the staff of Department of Radiology and Histopathology, Aga Khan University, Pakistan for their cooperation in sample collection.

\section{References}

I. Alter MJ: Epidemiology of hepatitis $\mathbf{C}$ virus infection. World J Gastroenterol 2007, I3(I7):2436-244I.

2. Hamid S, Umar M, Alam A, Siddiqui A, Qureshi H, Butt J: PSG consensus statement on management of hepatitis $C$ virus infection - 2003. Jpma 2004, 54(3): $146-150$.

3. Raza SA, Clifford GM, Franceschi S: Worldwide variation in the relative importance of hepatitis $B$ and hepatitis $C$ viruses in hepatocellular carcinoma: a systematic review. British journal of cancer 2007, 96(7): I I27- I I 34.

4. Liang TJ, Heller T: Pathogenesis of hepatitis C-associated hepatocellular carcinoma. Gastroenterology 2004, I27(5 Suppl I):S62-7I.

5. Tillmann HL, Manns MP, Rudolph KL: Merging models of hepatitis C virus pathogenesis. Semin Liver Dis 2005, 25(I):84-92.

6. Morgan DO: Principles of CDK regulation. Nature 1995, 374(65 I 8): $13 \mid-134$.

7. Sherr CJ: Cancer cell cycles. Science 1996, 274(5293):1672-1677.

8. Houtgraaf JH, Versmissen J, Giessen WJ van der: A concise review of DNA damage checkpoints and repair in mammalian cells. Cardiovasc Revasc Med 2006, 7(3): 165-172.

9. Sherr CJ, Roberts JM: CDK inhibitors: positive and negative regulators of GI-phase progression. Genes Dev 1999, I3(I2): $150|-15| 2$.

10. Molinari M: Cell cycle checkpoints and their inactivation in human cancer. Cell Prolif 2000, 33(5):261-274.
II. Werling K, Szentirmay Z, Szepesi A, Schaff Z, Szalay F, Szabo Z, Telegdy L, David K, Stotz G, Tulassay Z: Hepatocyte proliferation and cell cycle phase fractions in chronic viral hepatitis $\mathbf{C}$ by image analysis method. Eur J Gastroenterol Hepatol 200I, 13(5):489-493.

12. Marshall A, Rushbrook S, Davies SE, Morris LS, Scott IS, Vowler SL, Coleman N, Alexander G: Relation between hepatocyte GI arrest, impaired hepatic regeneration, and fibrosis in chronic hepatitis C virus infection. Gastroenterology 2005, I 28(I):33-42.

13. Sarfraz S, Hamid S, Siddiqui A, Hussain S, Pervez S, Alexander G: Altered expression of cell cycle and apoptotic proteins in chronic hepatitis C virus infection. BMC microbiology 2008, 8: 133 .

14. Batts KP, Ludwig J: Chronic hepatitis. An update on terminology and reporting. The American journal of surgical pathology 1995, 19(12): : 409-I4I7.

15. Asselah T, Bieche I, Laurendeau I, Paradis V, Vidaud D, Degott C, Martinot $M$, Bedossa $P$, Valla $D$, Vidaud $M$, et al.: Liver gene expression signature of mild fibrosis in patients with chronic hepatitis $C$. Gastroenterology 2005, I 29(6):2064-2075.

16. Livak KJ, Schmittgen TD: Analysis of relative gene expression data using real-time quantitative PCR and the 2(-Delta Delta C(T)) Method. Methods (San Diego, Calif) 200I, 25(4):402-408.

17. Farinati F, Cardin R, D'Errico A, De Maria N, Naccarato R, Cecchetto A, Grigioni W: Hepatocyte proliferative activity in chronic liver damage as assessed by the monoclonal antibody MIB I Ki67 in archival material: the role of etiology, disease activity, iron, and lipid peroxidation. Hepatology 1996, 23(6): | 1468-1475.

18. Freeman A, Hamid S, Morris L, Vowler S, Rushbrook S, Wight DG, Coleman N, Alexander G]: Improved detection of hepatocyte proliferation using antibody to the pre-replication complex: an association with hepatic fibrosis and viral replication in chronic hepatitis C virus infection. J Viral Hepat 2003, I0(5):345-350.

19. Lake-Bakaar G, Mazzoccoli V, Ruffini L: Digital image analysis of the distribution of proliferating cell nuclear antigen in hepatitis $C$ virus-related chronic hepatitis, cirrhosis, and hepatocellular carcinoma. Dig Dis Sci 2002, 47(7): 1644-1648.

20. Okada T, lizuka N, Yamada-Okabe H, Mori N, Tamesa T, Takemoto N, Tangoku A, Hamada K, Nakayama H, Miyamoto T, et al:: Gene expression profile linked to $\mathrm{p} 53$ status in hepatitis $C$ virusrelated hepatocellular carcinoma. FEBS Lett 2003, 555(3):583-590.

21. Wurmbach E, Chen YB, Khitrov G, Zhang W, Roayaie S, Schwartz M, Fiel I, Thung S, Mazzaferro V, Bruix J, et al.: Genome-wide molecular profiles of HCV-induced dysplasia and hepatocellular carcinoma. Hepatology 2007, 45(4):938-947.

22. Lunz JG 3rd, Tsuji H, Nozaki I, Murase N, Demetris AJ: An inhibitor of cyclin-dependent kinase, stress-induced p2 I Waf-I/Cip-I, mediates hepatocyte mito-inhibition during the evolution of cirrhosis. Hepatology (Baltimore, Md) 2005, 4 I (6): I 262-I 271.

23. Blain SW, Massague J: Breast cancer banishes p27 from nucleus. Nat Med 2002, 8(10): 1076-1078.

24. Sun D, Ren H, Oertel M, Sellers RS, Zhu L: Loss of p27Kip I enhances tumor progression in chronic hepatocyte injuryinduced liver tumorigenesis with widely ranging effects on Cdk2 or Cdc2 activation. Carcinogenesis 2007, 28(9): | 859 - | 866.

25. Farazi PA, DePinho RA: Hepatocellular carcinoma pathogenesis: from genes to environment. Nat Rev Cancer 2006, 6(9):674-687.

26. Chan GK, Jablonski SA, Starr DA, Goldberg ML, Yen TJ: Human Zw 10 and ROD are mitotic checkpoint proteins that bind to kinetochores. Nat Cell Biol 2000, 2(I 2):944-947.

27. Fang $G, Y u$ H, Kirschner MW: The checkpoint protein MAD2 and the mitotic regulator $C D C 20$ form a ternary complex with the anaphase-promoting complex to control anaphase initiation. Genes \& development 1998, I 2(1 2): | 187|-| 883.

28. Wang Z, Cummins JM, Shen D, Cahill DP, Jallepalli PV, Wang TL, Parsons DW, Traverso G, Awad M, Silliman N, et al.: Three classes of genes mutated in colorectal cancers with chromosomal instability. Cancer research 2004, 64(9):2998-3001.

29. Michel LS, Liberal V, Chatterjee A, Kirchwegger R, Pasche B, Gerald W, Dobles M, Sorger PK, Murty VV, Benezra R: MAD2 haplo-insufficiency causes premature anaphase and chromosome instability in mammalian cells. Nature 200I, 409(68 I 8):355-359. 
30. Wang $X$, Jin DY, Ng RW, Feng $\mathrm{H}$, Wong YC, Cheung AL, Tsao SW: Significance of MAD2 expression to mitotic checkpoint control in ovarian cancer cells. Cancer research 2002, 62(6): 1662-1668.

\section{Pre-publication history}

The pre-publication history for this paper can be accessed here:

http://www.biomedcentral.com/1471-2334/9/125/pre pub

Publish with Bio Med Central and every scientist can read your work free of charge

"BioMed Central will be the most significant development for disseminating the results of biomedical research in our lifetime. " Sir Paul Nurse, Cancer Research UK

Your research papers will be:

- available free of charge to the entire biomedical community

- peer reviewed and published immediately upon acceptance

- cited in PubMed and archived on PubMed Central

- yours - you keep the copyright
BioMedcentral 